\title{
Clinical Learning Experiences of Nursing Students Using an Innovative Clinical \\ Partnership Model: A Non-Randomized Controlled Trial
}

Aileen W.K. Chan ${ }^{1 *}, \mathrm{PhD}$
Fiona W.K. Tang ${ }^{1}, \mathrm{PhD}$
Kai Chow Choi ${ }^{1}, \mathrm{PhD}$
Ting Liu ${ }^{1}$, PhD Student
Ruth E. Taylor-Piliae ${ }^{2}, \mathrm{PhD}$

${ }^{1}$ The Nethersole School of Nursing, The Chinese University of Hong Kong, Shatin, N.T., Hong Kong SAR

${ }^{2}$ College of Nursing, University of Arizona, 1305 N. Martin, PO Box 210203, Tucson, AZ 85721-0203

* Corresponding author: Aileen W. K. Chan

The Nethersole School of Nursing, Faculty of Medicine, Esther Lee Building, The Chinese University of Hong Kong, Shatin, N.T. Hong Kong SAR.

Tel : +85239434290

Fax : +85226035269

Email : aileenchan@cuhk.edu.hk

Acknowledgements: This project was funded by the Seeding Grant for Developing Teaching and Learning Strategies, from the Nethersole School of Nursing, the Chinese University of Hong Kong (NUR_TL_1617_2). 


\begin{abstract}
Background: Clinical practicum is a major learning component for pre-registration nursing students. Various clinical practicum models have been used to facilitate students' clinical learning experiences, employing both university-based and hospital-based clinical teachers. Considering the strengths and limitations of these clinical practicum models, along with nursing workforce shortages, we developed and tested an innovative clinical partnership model (CPM) in Hong Kong.
\end{abstract}

Objective: To evaluate an innovative CPM among nursing students actual and preferred clinical learning environment, compared with a conventional facilitation model (CFM).

Design: A non-randomized controlled trial examining students' clinical experiences, comparing the CPM (supervised by hospital clinical teacher) with the CFM (supervised by university clinical teacher).

Setting: One university in Hong Kong.

Participants: Pre-registration nursing students $(\mathrm{N}=331)$, including bachelor of nursing $(\mathrm{n}=246$ year three-BN) and masters-entry nursing $(\mathrm{n}=85$ year one-MNSP).

Methods: Students were assigned to either the CPM ( $n=48$ BN plus n=85 MNSP students) or the CFM ( $\mathrm{n}=198 \mathrm{BN}$ students) for their clinical practice experiences in an acute medicalsurgical ward. Clinical teachers supervised between 6-8 students at a time, during these clinical practicums (duration=4-6 weeks). At the end of the clinical practicum, students were invited to complete the clinical learning environment inventory (CLEI). Analysis of covariance was used to compare groups; adjusted for age, gender and prior work experience.

Results: A total of 259 students (mean age $=22$ years, $76 \%$ female, $81 \%$ prior work experience) completed the CLEI (78\% response rate). Students had higher scores on preferred 
versus actual experiences, in all domains of the CLEI. CPM student experiences indicated a higher preferred task orientation $(\mathrm{p}=0.004)$, while CFM student experiences indicated a higher actual $(\mathrm{p}<0.001)$ and preferred individualization $(\mathrm{p}=0.005)$. No significant differences were noted in the other domains.

Conclusions: The CPM draws on the strengths of existing clinical learning models and provides complementary methods to facilitate clinical learning for pre-registration nursing students. Additional studies examining this CPM with longer duration of clinical practicum are recommended.

Keywords: clinical practice model; clinical practicum; clinical teaching; nursing students 


\section{Introduction}

Clinical practicum is a major component of teaching and learning for pre-registration nursing students. It is in the arena of clinical education that nursing students have the opportunity to develop and apply essential clinical skills. Clinical practice also enables student nurses to be socialized into the professional role (Thomas et al., 2015). Clinical practicums are located in a variety of settings; each has its own complex social environment (Shivers et al., 2017). In these settings, nursing students have a role of learner under supervision, and active involvement contributing to patient care (Allan, Smith, \& O'Driscoll, 2011). The clinical environment combines the learning of new knowledge and the practicing of skills in actual clinical situations, which helps students to maintain their eagerness to learn (Bourgeois, Drayton, \& Brown, 2011). Suitable environments for clinical practice are critical for optimal learning experiences. The quality of clinical teaching and learning is affected by the staff-student relationship. It is the clinical teacher who exercises direct control and supervision over the activities of the nursing students in the respective units. Students' satisfaction with their clinical experience indicates a positive relationship between satisfaction and learning environment. Additionally, nursing students depend upon a supportive atmosphere (Pai, Lee, \& Chang, 2011) based on psychological and pedagogical aspects for clinical learning, such as, staff-student relationships with support and feedback (Newton, Jolly, Ockerby, \& Cross, 2012).

\section{Background}

Clinical practicums enable nursing students to apply theoretical knowledge to direct patient care. Best practices in nursing care are vital for successful clinical learning experiences and establishing relationships between staff and students (d'Souza, Karkada, Parahoo, \& Venkatesaperumal, 2015). Nursing students often express a lack of nursing theory integration 
into clinical practice. To remedy this scenario, a variety of clinical practicum models have been tried, such as preceptorship, collaborative learning units, dedicated learning units (DEU), facilitation and cluster models (Bourgeois et al., 2011; callaghan

\& Gamroth, 2008; Callaghan et al., 2009; Edgecombe et al., 1999; Gamroth et al, 2003; McKenna and Wellard, 2004; Nielsen et al., 2017).

The preceptorship model involves supervision of one nursing student by one hospital-based clinical teacher. The particular focus is on newly graduated nurses and nursing students in terms of knowledge, practical skills, confidence, clinical judgment, professional socialization and the smooth transition from novice to expert nurse (Nielsen et al., 2017). The preceptor (clinical nurse) acts as a role model, providing a learning environment where theoretical knowledge links with essential clinical skills (Elisabeth et al., 2009; Happell, 2009). Studies indicate that the preceptorship model promotes adaptive learning competencies along with role socialization of nursing students (Happell, 2009). However, not all healthcare facilities can offer the preceptorship model, and at times, there are staff shortages with demanding workloads for preceptors. When this happens, students may be assigned to provide only basic care, without sufficient opportunities to observe (or practice) more complex care and skills (Croxon and Maginnis, 2009).

In the collaborative learning unit model, rather than assigning students to one nurse, as is the case with preceptorship, all nurses in the practice unit are involved in mentoring and supporting students. The salient elements of this model are that the clinicians share the responsibility to teach the students, as students determine their own learning needs and goals for clinical practice (Callaghan et al., 2009). Students are able to work with several staff members and experience multiple approaches to patient care. The benefits of the collaborative learning unit model are that 
students articulate and take responsibility for their own learning needs and work at a level of independence (with registered nurse supervision), while clinical staff share responsibility for guiding and enhancing student learning. The limitations of this model include challenges in obtaining feedback about student progress, as no single member of the nursing staff is accountable, and continuity of student learning and progress is often lacking (Budgen and Gamroth, 2008; Callaghan et al., 2009).

The dedicated learning unit (DEU) originated in 1990s (Edgecombe et al., 1999), and involves collaboration between university and clinical institutions. An experienced nurse works as preceptor and supervises one to two nursing students. The academic faulty member overlooks 10-12 students, and is responsible for ensuring students have acquired relevant clinical knowledge to achieve their expected clinical learning outcomes. In this model, students demonstrate increased satisfaction and greater engagement with patients (Hunt et al., 2015). The challenges perceived by students are that some nurses are not keen to be a DEU nurse and that these nurses need to be critically evaluated and trained. The challenges felt by the DEU nurses are that their first responsibility is their patients and they feel that they do not have enough time with the students. Given the current nursing shortage, additional workloads on nurses is not an ideal strategy (Rhodes, Meyers, \& Underhill, 2012).

In the facilitation model, a university-based clinical teacher facilitates the learning experiences of a group of students (e.g., 8-10) at a healthcare facility (McKenna and Wellard, 2004). In this capacity, the clinical teacher is supernumerary though not an employee of the healthcare facility. Often times, the clinical teacher may not be familiar with the various policies and procedures at the healthcare facility. Students though, generally appreciate the instruction and support provided by the clinical teacher, as they are able to link theoretical concepts with 
clinical practice. Though at times, the clinical teacher supervises students on different units in the healthcare facility and may not be available when needed; resulting in students missing an opportunity to practice a new skill (Budgen and Gamroth, 2008).

In Australia, a cluster model was developed, as a means to support nursing students in the clinical environment (Bourgeois et al., 2011). The cluster model places a group of 8 students on one unit in a hospital. These students have a hospital-based clinical teacher from the unit they are working on, yet this clinical teacher is paid by the university to facilitate student learning. Since the clinical teacher is an employee of the healthcare facility, they can more readily foster students' skill development, confidence, and team work (Bourgeois et al., 2011). The downside to this type of model is that students may feel disconnected from the university and unable to discuss negative clinical experiences, should they arise.

Clinical teachers, whether hospital or university-based, have identified insufficiencies in these models; thus, new models for optimizing student learning in the clinical environment continue to be developed and tested (Bourgeois et al., 2011). Considering the strengths and limitations of these clinical practicum models, along with nursing workforce shortages, we developed and tested an innovative clinical partnership model (CPM) in Hong Kong. The Clinical Partnership Model

It is essential that a constructive clinical learning environment should have adequate opportunities for the development of nursing care confidence and competence, as well as a focus on student learning needs (Croxon and Maginnis, 2009). The university teacher is familiar with the nursing curriculum, students' learning needs, and desired outcomes set for each clinical practice, while the hospital-based clinical teacher is more familiar with the healthcare facility. Hence, a strong partnership between clinical and university teachers is considered as an 
important aspect of nursing clinical practicums (Löfmark et al., 2012). The connection between academic and industry partners has been recognized as valuable for both the facility's and faculty's profiles (Bourgeois et al., 2011).

In our innovative clinical partnership model (CPM), we placed a group of nursing students (i.e., 6-8) in an acute medical or surgical unit. Similar to the cluster model described above, students were supervised by a hospital-based clinical teacher (supernumerary). The university paid the hospital directly for providing the designated clinical teacher. All hospital-based clinical teachers in this study, held a bachelor of nursing degree or above and had more than five years of post-registration clinical experience. These clinical teachers were assigned by the hospital according to their specialized experience in specific clinical practice settings. Prior to the clinical practicums, the hospital-based clinical teachers attended a clinical teaching orientation program, which included clinical teaching and assessment courses provided by the university, to facilitate their planning and delivering of clinical teaching in order for students to achieve the desired clinical learning outcomes.

In our CPM, we included a university teacher, to act as a liaison between the university and hospital. The university teacher kept close contact with the hospital-based clinical teacher and students throughout the clinical practicum period. The university teacher visited the hospitalbased clinical teacher and nursing students regularly, and provided additional support, if needed. Students had the opportunity to share their feelings and experiences with the university teacher as well.

Prior to the clinical practicums, the university teacher met with the hospital-based clinical teacher, to provide information about intended clinical learning and assessment requirements, expected by the university. During these meetings, the clinical teachers had the opportunity to 
ask questions to ensure an optimal learning environment for the nursing students. We tested our CPM in three local public hospitals and assessed students' clinical learning experiences, compared to the conventional facilitation model (CFM) in place.

\section{Methods}

Study design

We employed a non-randomized controlled trial examining students' clinical experiences, comparing the clinical partnership model (supervised by hospital clinical teacher) with the conventional facilitation model (supervised by university clinical teacher).

\section{Participants}

Participants were pre-registration nursing students recruited from one university in Hong Kong. All bachelor of nursing (BN) year three students and master of nursing science preregistration (MNSP) year one students were invited to participate in this study. The BN program is a 5-year full-time undergraduate program. The MNSP program is a master entry 3-year fulltime program. Students in the MNSP hold a bachelor's degree in another discipline, such as liberal arts, engineering, business or science. Prior to implementing this CPM, students had little exposure to the CFM (BN students completed only four-weeks of clinical, MNSP students completed only two-weeks of clinical, supervised by university teachers).

Our study sample ( $\mathrm{N}=331$ ) was sufficient for a two-group parallel comparison, to detect an effect size of 0.31 , at $5 \%$ level of significance with $80 \%$ power (Cohen, 1992). A total of 133 students were assigned to the CPM ( $\mathrm{n}=48 \mathrm{BN}$ plus $\mathrm{n}=85 \mathrm{MNSP}$ students), while $198 \mathrm{BN}$ students were assigned to the CFM for their clinical experiences in an acute medical-surgical ward. The differences in student allocation were according to individual program curriculum design. Clinical teachers supervised between 6-8 students at a time, during these clinical practicums 
(duration=4-6 weeks).

Study Measure

To assess the nursing students clinical learning experiences, we used the Clinical Learning Environment Inventory (CLEI), which assesses attributes associated with positive learning environments for students and has been widely used to examine nursing practice learning environments (Henderson et al., 2012). The CLEI was utilized to assess nursing students' perceptions of characteristics of the clinical learning environment during their clinical practicum (Chan, 2003). The CLEI consists of an Actual form (CLEI-A) which assesses the actual learning environment and the Preferred form (CLEI-P) which assesses students' desired clinical learning environment. The questions contained in the two CLEI forms are similar, with minor wording differences. The CLEI is a 42-item survey assessing six different domains: Personalization, Student Involvement, Satisfaction, Task Orientation, Innovation, and Individualization. Table 1 illustrates the definition of each domain, with examples of "actual" and "preferred" items for each domain for both actual and preferred learning environments. Each domain contains seven items, rated on a four-point Likert scale. CLEI scores for responses of strongly agree, agree, disagree and strongly disagree, are 5, 4, 2 and 1, respectively, with some questions scored in reverse. A score of 3 is assigned to incomplete, incorrect or missing responses. Higher scores indicate greater agreement associated with each domain. Internal consistency of the CLEI was reported, with Cronbach's alpha coefficients ranging from 0.50 to 0.80 for the CLEI-A and 0.51 to 0.76 for the CLEI-P (Chan and Ip, 2007). We included additional space at the end of the CLEI, to allow students to make further comments related to their clinical learning experiences. The questionnaire takes about 20-25 minutes to complete.

\section{Procedures}


Ethical approval was obtained from the Survey and Behavioral Research Ethics Committee of the Chinese University of Hong Kong. Following a class lecture, the purpose of the study was explained. Students were assured of confidentiality, and allowed the freedom to withdraw from the study at any time, without any adverse effect on their education. Following the clinical practicum testing the CPM, students were invited to complete an anonymous self-administered survey containing the CLEI actual and preferred forms, along with some demographic information, including age, sex and working experience. Those agreeing to participate, placed their completed survey in a sealed collection box, at the back of the classroom.

\section{Data analysis}

Descriptive statistics were used to summarize student demographics, along with the CLEI domain scores. Normality of variables with continuous data were assessed using skewness and kurtosis statistics and normal probability plot, and no deviation from normality of the continuous variables was found. Differences between groups (CPM versus CFM) were assessed using independent t-tests or chi-square tests for all demographic variables. Since age, gender and prior working experience were significantly different between groups (CPM versus CFM), we used analysis of covariance (ANCOVA) to compare students clinical learning experiences by group with adjustment for the above factors. The statistical tests involved were all 2-sided with level of significance set at 0.05 . All statistical analyses were conducted using IBM SPSS 23.0 (IBM Crop. Armonk, NY).

\section{Results}

A total of 259 students (mean age $=22$ years, $76 \%$ female, $81 \%$ prior work experience) completed the survey (78\% response rate). Students in the CPM group were older, with fewer females, though a larger proportion had prior full-time work experience (Table 2). 
Students had higher scores on preferred versus actual experiences, in all domains of the CLEI. In adjusted analyses, CPM student experiences indicated a higher preferred task orientation $(\mathrm{p}=0.004)$, while CFM student experiences indicated a higher preferred individualization $(\mathrm{p}=0.005)$. Regarding actual experiences, the only difference between the two groups was noted in the individualization domain, with CFM students experiencing higher individualization than the CPM group $(\mathrm{p}<0.001)$ (Table 3$)$.

A subgroup analysis was conducted to compare the subscale scores of the actual and preferred forms of the CLEI among the BN students between CFM ( $\mathrm{n}=157)$ and CPM ( $\mathrm{n}=38)$ groups. In adjusted analyses, the CPM students showed lower actual experiences in the satisfaction $(\mathrm{p}=0.024)$, task orientation $(\mathrm{p}=0.033)$ and individualization $(\mathrm{p}=0.005)$ domains, than the CFM students. Regarding preferred experiences, CPM students showed higher scores in the satisfaction and task orientation domains $(\mathrm{p}=0.033)$ and a lower score in the individualization domain ( $\mathrm{p}=0.028$ ), than CFM students (Table 4).

A further subgroup analysis was performed to compare the subscale scores of the actual and preferred forms of the CLEI between $\mathrm{BN}(\mathrm{n}=38)$ and MNSP $(\mathrm{n}=64)$ students in the CPM group, the only significant difference noted was in the actual experience in the individualization domain, with BN students experiencing higher individualization, than MNSP students ( $\mathrm{p}=0.04$ ) (Table 5).

Qualitative content analysis was not used to summarize written responses to the open-ended question, as only a handful of written comments were obtained. According to their open-ended comments, students generally had a positive view of the clinical learning experience. Students in the CPM group appreciated that the clinical teacher was familiar with environment on the unit. These CPM students also appreciated the ability to meet on a regular basis with the university 
teacher to discuss issues and receive support. One concern from students' feedback was the inconsistent requirements on clinical skill competency assessments among clinical teachers, which might affect the fairness of clinical examination. Students in the CFM group reported that the clinical teacher was supportive, though was not familiar with the environment on the unit, leading to challenges at the beginning of the practicum to engage students with the unit activities. These CFM students reported that having eight students per group was too large, as the clinical teacher was too busy and unable to provide sufficient support and individual guidance.

\section{Discussions}

In this study, we tested a clinical partnership model (CPM) among pre-registration nursing students, examining their actual and preferred perceptions of the characteristics of the clinical learning environment, compared with a conventional facilitation model (CFM). We found that students had higher preferred experiences than actual experiences in all domains of the CLEI in both models; which is consistent with other studies conducted locally and internationally (Brown et al., 2011; Chan \& Ip, 2007; Papathanasiou et al., 2014). With students' actual and preferred experiences in the clinical learning environment, the achievement of certain outcomes of clinical practicums might be enhanced by attempting to change the actual clinical learning environment in ways that make it more congruent with that preferred by the students (Chan, 2003). This indicates that clearer expectations at the beginning of the clinical practicum, communicated by the clinical teacher to the students are needed. A better understanding of what makes an excellent clinical practicum from the students' views would be valuable in providing better clinical learning experiences.

Similar to the cluster model developed in Australia (Bourgeois et al., 2011), our CPM placed a group of six to eight nursing students on one nursing unit. The CPM clinical teachers 
were supernumerary though employees of the healthcare facility. They were registered nurses with more than five years' post-registration experiences, and were familiar with the unit, hospital policies, and electronic clinical management system access. Thus, they were able to design learning activities for students to mirror real-world tasks of nursing professionals in an acute clinical setting such as teamwork, and communication with other healthcare disciplines.

Students in the CPM group had higher preferred task orientation scores than students in the CFM group. Task orientation assessed the degree to which activities on the unit are clear and well organized (Chan, 2003). Students likely expected to receive clear, well-planned, specific task assignments; as the CPM hospital-based clinical teacher is familiar with the hospital policies and clinical environment, unlike the CFM university-based clinical teacher.

On the other hand, students in the CFM group had higher actual and preferred individualization scores than students in the CPM group. The individualization domain assessed the extent to which students were allowed to make decisions and were treated differentially according to their ability or interest (Chan, 2003). The CFM clinical teachers likely had greater information about these students and their capabilities, allowing them to work more independently, unlike the CPM clinical teacher (Elisabeth et al., 2009; Lofmark et al., 2012). Prior research studies have reported that satisfaction is designed as an outcome measure and is positively associated with all other domains of the CLEI (Papathanasiou et al., 2014). Prior research found that nursing students rated higher satisfaction for the supervision by university teachers than clinical teachers (Löfmark et al., 2012). In Löfmark and colleagues' study, the higher rating for university teacher supervision might be explained by university teachers who were more familiar with the clinical practicum learning outcomes, and that fulfillment of learning outcomes was strongly associated with supervision by university teachers. 
Kristofferzon, Mårtensson, Mamhidir, and Löfmark (2013) also stated that university teachers were perceived as essential for critical thinking, reflection and exchange of experiences between students. However, these findings are in contrast to another study (Bourgeois et al., 2011), reporting that the hospital-based clinical teacher was always present in the ward, that students perceived having more practical experiences and increased opportunities to practice skills with supervision, even though there were several students practicing on the same ward. In our study, students were supervised by clinical teachers and connected with university teachers, which may in part help explain the similar level of satisfaction among students in either CPM or CFM.

The domain of personalization in this study was the one with the highest score in the actual form of the CLEI. Given that the domain of personalization assessed opportunities for the individual student to interact with their clinical teacher or university teacher, demonstrating concern for student's personal welfare (Chan, 2003), the clinical practicum using either model was highly regarded by students in the actual clinical learning environment.

Our study also compared the results of CLEI among BN students between CPM and CFM, with BN students in the CPM group indicating lower actual satisfaction. Although this finding seems to favor the CFM (university teacher) and is similar to Löfmark et al.'s study (2012), these findings must be interpreted cautiously as a limited number of BN students were in CPM ( $\mathrm{n}=38)$ compared to CFM ( $\mathrm{n}=157)$. Additionally, the duration of the clinical practicum is associated with level of satisfaction.

Among an exploratory study examining the clinical learning experience of nurse students in nine European counties, a seven-week clinical practicum placement resulted in greater student satisfaction (Warne et al., 2010). In our study, the duration of the clinical practicum was between four to six weeks, thus the limited time period for students to integrate their clinical skills and 
develop their interpersonal skills for building effective and therapeutic relationships with their patients may have impacted their level of satisfaction (Warne et al., 2010). Future studies may like to incorporate a longer clinical practicum time-period, e.g., 10-12 weeks, when examining students' clinical learning experiences using different clinical practicum models.

When comparing the BN ( $\mathrm{n}=38$ ) and MNSP ( $\mathrm{n}=64)$ students' perceptions using CPM, differences were reported only in the actual experience of individualization subscale, with the BN students rating this higher than the MNSP students. This suggests that MNSP students generally experienced a less than positive clinical learning experience related to individualization issues. The lower individualization scores among the MNSP students might be due to differences in age, study year or prior work experience (Shivers et al., 2017). As stated by Chan and Ip (2007), year one in the MNSP is perceived as a transitional period for these nursing students to engage in brand new healthcare experiences. The year three BN students likely had developed a greater insight into the learning environment, contributing to the higher score in this individualization domain. Future studies should take this issue into consideration and explore the influence of students' age, study year and prior work experiences on their clinical learning experiences.

In our CPM, students benefited by having a hospital-based clinical teacher to facilitate their learning in the clinical environment, as well as a university teacher visiting them on a regular basis in the clinical environment. University teachers' visits were considered to have great value not only because they provided nursing students with support, but also the prospect of a visit motivated students to carry out preparatory work and discuss learning outcomes (Kristofferzon et al., 2013). The university teacher acted as a liaison between the clinical site and the university, fostering communication in terms of expected learning outcomes; while being a resource to 
students encountering challenges.

In addressing the CPM students' concern of inconsistent standards on clinical skill competency assessments, apart from a pre-clinical meeting and briefing, an inter-rater reliability test for all clinical teachers involved in skill assessments needs to be conducted prior to the commencement of clinical practicums. This strategy would certainly minimize discrepancies in skill competency standards and maintain clinical assessment consistencies.

\section{Study Limitations}

In our study, pre-registration nursing students that agreed to participate represented only one university in Hong Kong, the findings might not be representative of nursing students in general with respect to their clinical placements. While the CLEI is a valid, self-reported questionnaire, the responses provided may have been answered in a socially acceptable or desired manner, without being a true representation of participants' perceptions. Additionally, the CLEI tool may focus more on the depiction of students' views and their expectations from clinical training in one existing clinical setting. As commented by Newton et al. (2010), students' responses to CLEI items are influenced by the type of clinical placement and their study years. Since our study results were derived from a heterogeneous group of students and clinical learning environments, Chan's tool might not account for the variance in learning across difference levels of students and environments due to heterogeneous group of Year 2 students (Newton et al., 2010). Further research to examine different clinical locations and different levels of students' CLEI responses, with a stringent RCT study design might offer critical insights into the actual influence.

Furthermore, a face-to-face focus group interview is recommended going forward, as this would lead to a better understanding of students' clinical learning experiences when learning according to either CPM or CFM. Finally, we used a non-randomized controlled trial to test the CPM and 
CFM for clinical learning experiences, and we found nonequivalence between these groups on some demographic characteristics; although proper statistical adjustments were made in the analyses, the findings might be confounded by some unidentified factors. Despite these limitations, our study provides important findings to explore a new and improved model for clinical learning experiences of pre-registration nursing students.

\section{Conclusion}

Our innovative CPM draws on the strengths of existing clinical models and provides complementary methods to facilitate clinical teaching for pre-registration nursing students. The CPM clinical teacher is familiar with the clinical environment and can foster learning experiences that a CFM clinical teacher may not have knowledge of or access to. The strength of the CPM is that students also have regular contact with a university teacher, even though their clinical teacher is employed by the clinical facility. Clinical practicums are a vital part of nursing education. Both university-based teachers and hospital-based clinical teachers have unique roles in clinical teaching and learning. Hospital-based clinical teachers are experts in clinical settings, while the university-based teachers provide a theoretical perspective of teaching and learning to nursing students. Additional studies examining this CPM with longer duration and employing mixed methods designs using randomized controlled studies along with descriptive qualitative data derived from interviews are recommended, to determine if student learning is enhanced, and outcomes of the clinical practicum are achieved. 


\section{References}

Allan, H. T., Smith, P., \& O'Driscoll, M. (2011). Experiences of supernumerary status and the hidden curriculum in nursing: A new twist in the theory-practice gap? Journal of Clinical Nursing, 20(5-6), 847-855.

Bourgeois, S., Drayton, N., \& Brown, A. M. (2011). An innovative model of supportive clinical teaching and learning for undergraduate nursing students: the cluster model. Nurse Education Practice, 11(2), 114-118.

Brown, T., Williams, B., McKenna, L., Palermo, C., McCall, L., Roller, L., Hewitt, L., Molloy, L., Baird, M., Aldabah, L. (2011). Practice education learning environments: the mismatch between perceived and preferred expectations of undergraduate health science students. Nurse Education Today, 31(8), e22-28.

Budgen, C., \& Gamroth, L. (2008). An overview of practice education models. Nurse Education Today, 28 (3), 273- 283.

Callaghan, D., Watts, W. E., McCullough, D. L., Moreau, J. T., Little, M. A., Garmroth, L. M., Drnford, K. L. (2009). The experience of two practice education models: Collaborative learning unit an preceptorship. Nurse Education Today, 9, 244-252.

Chan, D. S. (2003). Validation of the Clinical Learning Environment Inventory. Western Journal of Nursing Research, 25(5), 519-532.

Chan, D.S.K. \& Ip, W.Y. (2007). Perception of hospital learning environment: A survey of Hong Kong nursing students. Nurse Education Today, 27, 677-684.

Cohen, J. (1992). A power primer. Psychological Bulletin, 112(1), 155.

Croxon, L., \& Maginnis, C. (2009). Evaluation of clinical teaching models for nursing practice. Nurse Education Practice, 9(4), 236-243.

d'Souza, M. S., Karkada, S. N., Parahoo, K., \& Venkatesaperumal, R. (2015). Perception of and satisfaction with the clinical learning environment among nursing students. Nurse Education Today, 35(6), 833-840.

Edgecombe, K., Wotton, K., Gonda, J., \& Mason, P. (1999). Dedicated education units: A new concept for clinical teaching and learning. Contemporary Nurse, 8(4), 166-171.

Elisabeth, C., Christine, W. H., \& Ewa, P. (2009). Teaching during clinical practice: strategies and techniques used by preceptors in nursing education. Nurse Education Today, 29(5), $522-526$. 
Happell, B. (2009). A model of preceptorship in nursing: reflecting the complex functions of the role. Nursing Education Perspectives, 30(6), 372-376.

Henderson, A., Cooke, M., Creedy, D. K., \& Walker, R. (2012). Nursing students' perceptions of learning in practice environments: A review doi:https://doi.org/10.1016/j.nedt.2011.03.010

Hunt, D. A., Milani, M. F., Wilson, S. (2015). Dedicated education units: An innovative model for clinical education. American Nurse Today, 2015, 10, 5, 46-49.

Kristofferzon, M. L., Mårtensson, G., Mamhidir, A. G., \& Löfmark, A. (2013). Nursing students' perceptions of clinical supervision: The contributions of preceptors, head preceptors and clinical lecturers. Nurse education today, 33(10), 1252-1257.

Levett-Jones, T., Lathlean, J., Higgins, I., \& McMillan, M. (2009). Staff-student relationships and their impact on nursing students' belongingness and learning. Journal of advanced nursing, 65(2), 316-324.

Lofmark, A., Thorkildsen, K., Raholm, M. B., \& Natvig, G. K. (2012). Nursing students' satisfaction with supervision from preceptors and teachers during clinical practice. Nurse Education in Practice, 12(3), 164-169.

McKenna, L. G., \& Wellard, S. J. (2004). Discursive influences on clinical teaching in Australian undergraduate nursing programs. Nurse Education Today, 24(3), 229-235.

Newton, J. M., Jolly, B. C., Ockerby, C. M., \& Cross, W. M. (2010). Clinical learning environment inventory: Factor analysis. Journal of Advanced Nursing, 66(6), 1371-1381.

Newton, J. M., Jolly, B. C., Ockerby, C. M., \& Cross, W. M. (2012). Student centredness in clinical learning: the influence of the clinical teacher. Journal of advanced nursing, 68(10), 2331-2340.

Nielsen, K., Finderup, J., Brahe, L., Elgaard R, Elsborg, A.M., Engell-Soerensen, V., Holm, L., Juul, H., Sommer, I., 2017. The art of preceptorship. A qualitative study. Nurse Educ Pract. 26:39-45.

Pai, H. C., Lee, S., \& Chang, T. (2011). A confirmatory factor analysis of the clinical nursing practice environment scale with hospital registered nurses in Taiwan. Journal of clinical nursing, 20(15-16), 2344-2354.

Papathanasiou, I. V., Tsaras, K., \& Sarafis, P. (2014). Views and perceptions of nursing students on their clinical learning environment: teaching and learning. Nurse Education Today, 34(1), 57-60. 
Rhodes, M., Meyers, C.C., \& Underhill, M.L., (2012). Evaluation outcomes of a dedicated education unit in a baccalaureate nursing program. Journal of Professional Nursing, 28(4), 223-230.

Shivers, E., Hasson, F., \& Slater, P. (2017). Pre-registration nursing student's quality of practice learning: Clinical learning environment inventory (actual) questionnaire. Nurse Education Today, 55, 58-64.

Thomas, J., Jinks, A., \& Jack, B. (2015). Finessing incivility: The professional socialisation experiences of student nurses' first clinical placement, a grounded theory. Nurse Education Today., 35(12):e4-9. doi:https://doi.org/10.1016/j.nedt.2015.08.022

Warne, T., Johansson, U., Papastavrou, E., Tichelaar, E., Tomietto, M., Van den Bossche, K., Moreno, M.F., Saarikoski, M. (2010). An exploration of the clinical learning experience of nursing students in nine European countries. Nurse Education Today, 30(8), 809-815. 
Table 1: Description of the Clinical Learning Environment Inventory subscales

\begin{tabular}{|c|c|c|c|}
\hline Scale name & Scale description & Example of actual item & $\begin{array}{l}\text { Example of preferred } \\
\text { item }\end{array}$ \\
\hline Personalization & $\begin{array}{l}\text { Emphasis on opportunities } \\
\text { for individual student to } \\
\text { interact with clinical } \\
\text { teacher/clinician and on } \\
\text { concern for student's } \\
\text { personal welfare. }\end{array}$ & $\begin{array}{l}\text { The clinical teacher } \\
\text { considers student's } \\
\text { feelings. }\end{array}$ & $\begin{array}{l}\text { The clinical teacher } \\
\text { should considers } \\
\text { student's feelings. }\end{array}$ \\
\hline $\begin{array}{l}\text { Student } \\
\text { involvement }\end{array}$ & $\begin{array}{l}\text { Extent to which students } \\
\text { participate actively and } \\
\text { attentively in hospital ward } \\
\text { activities. }\end{array}$ & $\begin{array}{l}\text { There are opportunities } \\
\text { for students to express } \\
\text { opinions in this ward. }\end{array}$ & $\begin{array}{l}\text { There should be } \\
\text { opportunities for } \\
\text { students to express } \\
\text { opinions in this ward. }\end{array}$ \\
\hline Satisfaction & $\begin{array}{l}\text { Extent of students' } \\
\text { enjoyment of clinical } \\
\text { placements. }\end{array}$ & $\begin{array}{l}\text { This clinical placement } \\
\text { is interesting. }\end{array}$ & $\begin{array}{l}\text { This clinical placement } \\
\text { should be interesting. }\end{array}$ \\
\hline Task orientation & $\begin{array}{l}\text { Extent to which ward } \\
\text { activities are clear and well } \\
\text { organized. }\end{array}$ & $\begin{array}{l}\text { Students know } \\
\text { exactly what has } \\
\text { to be done in the ward. }\end{array}$ & $\begin{array}{l}\text { Students should know } \\
\text { exactly what has to be } \\
\text { done in the ward. }\end{array}$ \\
\hline Innovation & $\begin{array}{l}\text { Extent to which clinical } \\
\text { teacher/clinician plans new, } \\
\text { interesting, and productive } \\
\text { ward experiences, teaching } \\
\text { techniques, learning } \\
\text { activities and patient } \\
\text { allocations. }\end{array}$ & $\begin{array}{l}\text { The clinical teacher } \\
\text { thinks up innovative } \\
\text { activities for students. }\end{array}$ & $\begin{array}{l}\text { The clinical teacher } \\
\text { should think up } \\
\text { innovative activities for } \\
\text { students. }\end{array}$ \\
\hline Individualization & $\begin{array}{l}\text { Extent to which students } \\
\text { are allowed to make } \\
\text { decisions and are treated } \\
\text { differentially according to } \\
\text { ability or interest. }\end{array}$ & $\begin{array}{l}\text { Students are generally } \\
\text { allowed to work at their } \\
\text { own pace. }\end{array}$ & $\begin{array}{l}\text { Students should } \\
\text { generally be allowed to } \\
\text { work at their own pace. }\end{array}$ \\
\hline
\end{tabular}

Source: Chan, 2003 
Table 2: Background characteristics of the pre-registration nursing students $(\mathrm{N}=259)$

\begin{tabular}{|c|c|c|c|c|}
\hline Characteristics & $\begin{array}{l}\text { All students } \\
(\mathrm{N}=259)\end{array}$ & $\begin{array}{c}\text { CFM students } \\
(\mathrm{n}=157)\end{array}$ & $\begin{array}{l}\text { CPM students } \\
(\mathrm{n}=102)\end{array}$ & p-value \\
\hline \multicolumn{5}{|l|}{ Demographics } \\
\hline Age, years ${ }^{\dagger}$ & $22.2(2.1)$ & $21.3(0.6)$ & $23.8(2.7)$ & $<0.001^{\mathrm{a}}$ \\
\hline Female gender & $196(76.0 \%)$ & $126(80.3 \%)$ & $70(69.3 \%)$ & $0.045^{\mathrm{b}}$ \\
\hline Religious beliefs & $65(25.1 \%)$ & $41(26.1 \%)$ & $24(23.5 \%)$ & $0.639^{b}$ \\
\hline \multicolumn{5}{|c|}{ Working experience } \\
\hline No & $49(19.1 \%)$ & $35(22.3 \%)$ & $14(14.0 \%)$ & $<0.001^{\mathrm{b}}$ \\
\hline Part-time only & $153(59.5 \%)$ & $119(75.8 \%)$ & $34(34.0 \%)$ & \\
\hline Full-time & $55(21.4 \%)$ & $3(1.9 \%)$ & $52(52.0 \%)$ & \\
\hline
\end{tabular}

$\overline{\mathrm{CFM}}=$ conventional facilitation model; $\mathrm{CPM}=$ cluster partnership model; $\uparrow$ mean (standard deviation), other data presented as frequency (percentage); ${ }^{a}$ Independent t-test; ${ }^{\mathrm{b}} \mathrm{Chi}$-square test 
Table 3: Subscale scores of the Clinical Learning Environment Inventory according to group

\begin{tabular}{|c|c|c|c|c|}
\hline CLEI Subscales ${ }^{\#}$ & $\begin{array}{c}\text { CFM students } \\
(\mathrm{n}=157)\end{array}$ & $\begin{array}{c}\text { CPM students } \\
(\mathrm{n}=102)\end{array}$ & $p$-value ${ }^{a}$ & $p$-value ${ }^{b}$ \\
\hline \multicolumn{5}{|l|}{ Personalization } \\
\hline Actual experience & $27.5(4.0)$ & $27.1(4.8)$ & 0.415 & 0.428 \\
\hline Preferred experience & $29.5(3.2)$ & $29.5(3.1)$ & 0.943 & 0.185 \\
\hline
\end{tabular}

$\underline{\text { Student involvement }}$

Actual experience

$24.5(3.4)$

$23.9(3.9)$

$0.257 \quad 0.834$

Preferred experience

$27.8(2.9)$

$27.9(3.4)$

0.936

0.211

$\underline{\text { Satisfaction }}$

Actual experience

$26.9(4.4)$

$26.0(6.1)$

0.166

0.122

Preferred experience

$29.8(3.0)$

$30.6(3.1)$

0.036

0.062

$\underline{\text { Task orientation }}$

$\begin{array}{lllll}\text { Actual experience } & 27.2(3.1) & 26.7(3.7) & 0.289 & 0.143 \\ \text { Preferred experience } & 29.6(2.8) & 30.4(3.0) & 0.040 & 0.004\end{array}$

$\underline{\text { Innovation }}$

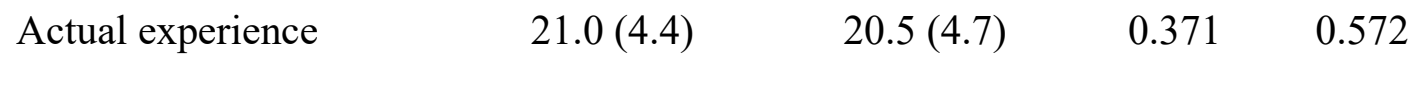

Preferred experience

$25.6(3.2)$

$24.5(3.6)$

$0.015 \quad 0.612$

$\underline{\text { Individualization }}$

Actual experience

$20.5(4.6)$

$<0.001$

$<0.001$

Preferred experience

$26.9(3.2)$

$24.6(3.7)$

$<0.001$

0.005

$\overline{\mathrm{CFM}}=$ conventional facilitation model; $\mathrm{CPM}=$ cluster partnership model; $\mathrm{CLEI}=\mathrm{Clinical}$ Learning Environment Inventory; ${ }^{\mathrm{a} U n a d j u s t e d ~ g r o u p ~ c o m p a r i s o n s ~ a m o n g ~ u s i n g ~ i n d e p e n d e n t ~ t-t e s t s ; ~}{ }^{\mathrm{b}} \mathrm{Group}$ comparisons adjusted for age, gender and prior work experience using ANCOVA; \#range of CLEI subscale scores $=7$ to 35 , presented as mean (standard deviation). 
Table 4: Subscale scores of the Clinical Learning Environment Inventory of the BN students according to group

\begin{tabular}{lcccc}
\hline CLEI Subscales & $\begin{array}{c}\text { CFM BN } \\
\text { students }(\mathrm{n}=157)\end{array}$ & $\begin{array}{c}\text { CPM BN } \\
\text { students }(\mathrm{n}=38)\end{array}$ & p-value $^{\text {a }}$ & p-value $^{\mathrm{b}}$ \\
\cline { 3 - 5 } Actual experience & $27.5(4.0)$ & $26.3(5.7)$ & 0.135 & 0.283 \\
Preferred experience & $29.5(3.2)$ & $30.6(2.4)$ & 0.048 & 0.061
\end{tabular}

Student involvement

Actual experience

$23.9(3.8)$

0.418

0.765

Preferred experience

$27.8(2.9)$

28.5 (2.9)

0.232

0.120

$\underline{\text { Satisfaction }}$

$\begin{array}{lllll}\text { Actual experience } & 26.9(4.4) & 24.7(7.2) & 0.016 & 0.024 \\ \text { Preferred experience } & 29.8(3.0) & 30.9(2.7) & 0.034 & 0.033\end{array}$

\section{Task orientation}

Actual experience

$27.2(3.1)$

$25.7(4.6)$

$0.016 \quad 0.033$

Preferred experience

$29.6(2.8)$

$31.4(2.7)$

$<0.001<0.001$

$\underline{\text { Innovation }}$

Actual experience

$20.7(5.5)$

0.680

0.683

Preferred experience

$25.6(3.2)$

$25.6(3.2)$

0.947

0.824

$\underline{\text { Individualization }}$

Actual experience

$21.1(4.5)$

0.005

0.005

Preferred experience

$26.9(3.2)$

$25.6(2.3)$

0.017

0.028

$\overline{\mathrm{CFM}}=$ conventional facilitation model; $\mathrm{CPM}=$ cluster partnership model; $\mathrm{CLEI}=\mathrm{Clinical}$ Learning Environment Inventory; ${ }^{\mathrm{a} U n a d j u s t e d ~ g r o u p ~ c o m p a r i s o n s ~ a m o n g ~ u s i n g ~ i n d e p e n d e n t ~ t-t e s t s ; ~}{ }^{\mathrm{b}} \mathrm{Group}$ comparisons adjusted for age, gender and prior work experience using ANCOVA; \#range of CLEI subscale scores $=7$ to 35 , presented as mean (standard deviation). 
Table 5: Subscale scores of the of the Clinical Learning Environment Inventory between BN and MNSP students, following CPM

\begin{tabular}{lcccc}
\hline CLEI Subscales & $\begin{array}{c}\text { CPM-BN } \\
\text { students }(\mathrm{n}=38)\end{array}$ & $\begin{array}{c}\text { CPM-MNSP } \\
\text { students }(\mathrm{n}=64)\end{array}$ & p-value $^{\text {a }}$ & p-value $^{\mathrm{b}}$ \\
\cline { 3 - 5 } Personalization & $26.3(5.7)$ & $27.5(4.1)$ & 0.229 & 0.533 \\
Actual experience & $30.6(2.4)$ & $28.9(3.3)$ & 0.006 & 0.102 \\
Preferred experience & & &
\end{tabular}

Student involvement

Actual experience

$23.9(3.9)$

0.990

0.710

Preferred experience

28.5 (2.9)

$27.5(3.6)$

0.164

0.594

$\underline{\text { Satisfaction }}$

Actual experience

24.7 (7.2)

$26.8(5.2)$

0.092

0.171

Preferred experience

30.9 (2.7)

$30.4(3.3)$

0.400

0.464

\section{$\underline{\text { Task orientation }}$}

Actual experience

$25.7(4.6)$

$27.4(2.9)$

0.023

0.078

Preferred experience

$31.4(2.7)$

$29.7(3.1)$

$0.007 \quad 0.084$

Innovation

Actual experience

$20.7(5.5)$

$20.4(4.1)$

0.781

0.803

Preferred experience

$25.6(3.2)$

$23.9(3.8)$

0.018

0.318

$\underline{\text { Individualization }}$

Actual experience

$20.1(4.6)$

$0.277 \quad 0.040$

Preferred experience

$25.6(2.3)$

$24.0(4.2)$

0.027

0.198

$\mathrm{CPM}=$ cluster partnership model; CLEI= Clinical Learning Environment Inventory; ${ }^{\text {a Unadjusted group }}$ comparisons among using independent t-tests; ${ }^{\mathrm{b}} \mathrm{Group}$ comparisons adjusted for age, gender and prior work experience using ANCOVA; \#range of CLEI subscale scores=7 to 35, presented as mean (standard deviation). 